\title{
Implantação Do Progama De Qualidade 8s No Segmento De Construção Civil Em Palmeiras De Goiás
}

\author{
Roseli Vieira Pires ${ }^{1}$ Diego Eduardo Lima de Souza ${ }^{2}$ Gislaine Silva Leite ${ }^{3}$ \\ ${ }^{1}$ Doutora em Psicologia pela PUC-GO; Estágio pós-doutoral em Psicologia pela PUC-GO; \\ Estágio pós-doutoral em Geografia pela UFG; Mestre em Desenvolvimento Organizacional pela \\ FACECA-MG; Professora do Instituto Aphonsiano de Ensino Superior; Professora da Universidade Estadual \\ de Goiás. \\ ${ }^{2}$ Graduado em Administração, pelo Instituto Aphonsiano de ensino superior, 2020. \\ ${ }^{3}$ Graduanda em Administração pelo Instituto Aphonsiano de ensino superior, 2020.
}

RESUMO - O presente trabalho de conclusão de curso tem como objetivo mostrar a implantação do programa de gestão da qualidade do 8 s nas empresas. A adoção desse método de qualidade traz inúmeros benéficos e melhorias para a instituição e para os colaboradores. O programa da qualidade do 8 s busca aprimorar o ambiente da empresa e buscar a elevação contínua nos processos, através de redução de falhas, organização de processos e ainda prevenir acidentes e doenças do trabalho. Foi utilizada a metodologia de pesquisa bibliográfica e pesquisa qualitativa a partir da aplicação de um questionário de entrevista sobre o programa de qualidade 8 s com os colaboradores da empresa. A aplicação do questionário ocorreu com os colaboradores da empresa Hozanna Construções que atua no ramo da construção civil. A implantação do programa de qualidade $8 s$ traz inúmeras e grandes mudanças positivas e resultados significativos para a empresa e para os colaboradores.

Palavras chave: Programa de Qualidade. Processos. Implantação.

\begin{abstract}
The purpose of this final course work is to show the implementation of the 8s quality management program in companies. The adoption of this quality method brings countless benefits and improvements for the institution and employees. The 8 s quality program seeks to improve the company's environment and seek continuous improvement in processes, through the reduction of failures, the organization of processes and the prevention of accidents and occupational diseases. The bibliographic and qualitative research methodology was used based on the application of an interview questionnaire about the 8s quality program with the company's employees. The questionnaire was applied to employees of the company Hozanna Construções, which operates in the civil construction sector. The implementation of the 8 s quality program brings countless and great positive changes and significant results for the company and employees.
\end{abstract}

Keywords: Quality Program. Law Suit. Implantation.

\section{INTRODUÇÃO}

No Brasil, a indústria da construção civil sobrevive dentro de um cenário político, econômico, e social bastante variável. Este panorama complexo e heterogêneo exige do setor uma constante capacidade de adaptabilidade. Por isso,o mercado está se tornando cada vez mais exigente no que diz respeito a aumentar a qualidade, ao mesmo tempo em que reduz os custos, pois, desse modo, a obra pode ser executada gerando lucro 
para a empresa.Mas antes de tudo, é preciso que ela seja efetuada da forma correta, além disso, um bom planejamento e gerenciamento de todas as suas etapas é essencial.

Entretanto, devido ao crescimento da construção civil acabou se tornando indispensável a gestão da qualidade, sendo assim, tem-se maior exigência por produtos e serviços que se destacam no mercado. Assim, a gestão da qualidade passa a contribuir para a busca de estratégias e diferenciações que objetivam a satisfação dos colaboradores e clientes. Com esse fim, foram criadas ferramentas para permitir uma maior eficiência na gestão.

Uma dessas estratégias é o Programa 5S, que é considerado como o ponto inicial para a introdução da qualidade nas empresas. Esse programa é capaz de proporcionar diversos benefícios para a implementação da ordem organizacional, elevando a capacidade para o discernimento dos indivíduos.

$\mathrm{Na}$ busca de uma melhor forma para se chegar aos inúmeros benefícios para uma organização, a partir do programa $5 \mathrm{~S}$, nasceu o $8 \mathrm{~S}$, um derivado que tem como principal objetivo o combate aos desperdícios, que tem por finalidade treinar os colaboradores e aprimorar a qualidade dos seus processos.

A grande vantagem do programa $8 \mathrm{~S}$ é que ele não abrange investimentos em automação ou máquinas, mas uma gestão voltada principalmente para a gerência dos recursos humanos e materiais, baseando-se principalmente na capacidade, criatividade e qualificação das pessoas. Isso porque ao aderir a esse programa, o pessoal da empresa passa a ser um grupo unido que visa à economia, organização e o combate aos desperdícios.

A partir da necessidade de apresentar conceitos teóricos da Gestão da qualidade e do Programa de qualidade $8 \mathrm{~S}$, e sua importância para as organizações com foco na construção civil, o presente trabalho tem como objetivo, verificar como a implantação do programa $8 \mathrm{~S}$ pode trazer inúmeros benefícios para a organização e para os colaboradores da construção civil.

Desse modo, esta pesquisa encontra relevância a partir do ponto que, a implantação do programa $8 \mathrm{~S}$ pode ser a porta de entrada para a inserção de um sistema de gestão da qualidade na empresa.Pois, dentre os grandes desafios que a construção civil enfrenta, está a manutenção da organização nos canteiros de obra, mas a implantação desse programa como meio para o gerenciamento da qualidade, pode trazer diversos benefícios, tais como: eliminar o excesso de materiais, ferramentas e entulhos, disponibilizando maior espaço, reduzindo os desperdícios e economizando tempo.Além disso, estimula o trabalho em equipe e melhora a aparência do canteiro de obras.

Para isso, o presente estudo, foi realizado a partir de uma abordagem metodológicaexploratória de caráter quali-quantitativa, por meio de um estudo de caso, que teve suporte de uma revisão bibliográfica que trouxe os conceitos sobre a gestão da qualidade e o programa 8S. O estudo está dividido da seguinte forma: fundamentação teórica, que levanta os conceitos de qualidade 8S a partir de autores:Garvin (2002), Abrantes (2007), Costa Neto e Canuto (2010), Lucinda (2010), Araújo (2012), Favoron (2012), Ambrozewicz (2015), dentre outros. Serão feitas análise e discussão dos resultados, a partir dos dados que foram levantados em campo junto aos colaboradores da empresa Hozanna Construções.

\subsection{GESTÃO DA QUALIDADE}

\section{IIFUNDAMENTAÇÃO TEÓRICA}

De acordo com Ambrozewicz (2015), uma das maiores dificuldades para a definição do termo qualidade com precisão é que além de não ser um termo técnico, o termo qualidade é de domínio público, e para a sua definição, é essencial a verificação das noções intuitivas que as pessoas possuem sobre esse vocábulo.

Desse modo, a maneira como a qualidade é entendida, depende de como ela reflete nas rotinas produtivas das empresas. Pois, a qualidade faz com que as empresas tenham que aprender a se movimentar de forma mais dinâmica, competitiva e criativa agregando aos seus produtos e serviços diferenciais que as coloque frente às outras empresas, para que assim possam crescer continuamente e garantir a sua sobrevivência.

Nessa perspectiva, conforme elenca Garvin (2002), em decorrência da dificuldade de conceituação do termo e das diferentes interpretações sobre a qualidade, é essencial que haja um entendimento mais profundo do termo, par que ele assuma um papel estratégico para a produtividade das empresas.

Uma definição ao termo qualidade é dada por Araújo (2012) quando o autor deduz que, a qualidade é definida como a busca pela perfeição com o objetivo de satisfazer os clientes que são mais exigentes. Essa filosofia busca a eliminação do retrabalho e tem como objetivo estar impecável, sem defeitos, assim, com a possibilidade de obter mais lucro.

No começo do século XX, a qualidade foi introduzida à produção industrial a fim de que os produtos de 
má qualidade não chegassem ao cliente final. Com o crescimento da produção em massa, apareceram novas técnicas de controle estatístico da qualidade de modo que os mercados passados fossem atendidos de maneira mais segura. Esta organização foi chamada de controle da Qualidade.

De acordo com Oliveira et. al. (2011), o primeiro indício da preocupação com a qualidade e com a satisfação dos clientes foi registrado no Código de Hamurabi por volta do ano 2.150 a.C, uma vez que esse regulamento demonstrava preocupações com a funcionalidade e a durabilidade das residências produzidas naquela época.

À medida que o tempo passou que foram surgindo as tecnologias e inovações, a qualidade evoluiu e assumiu suas diferentes abordagens que têm impacto direto na sua difícil definição. Mas, Costa Neto e Canuto (2010), afirmam que existe, entretanto, um consenso que define a qualidade a partir de cinco abordagens.

A primeira abordagem coloca a qualidade como algo transcendental, em que ela está relacionada com a excelência e com padrões de alto nível. A segunda abordagem compreende a qualidade como um conceito voltado para o produto, assim, ela se trata de uma variável que pode ser mensurada a partir dos atributos dos produtos (COSTA NETO; CANUTO, 2010).

A terceira abordagem coloca a qualidade como termo baseado no usuário.Nesse sentido, os produtos de qualidade são os que atendem, de forma plena, as exigências dos consumidores. A quarta abordagem baseia-se na produção, quando qualidade está relacionada com a conformidade entre o que foi planejado e o que foi executado no processo produtivo. Por fim, a quinta abordagem diz respeito ao valor, assim, qualidade e preço são duas variáveis que devem ser aceitáveis pelo consumidor (COSTA NETO; CANUTO, 2010).

De acordo com Lucinda (2010), apesar de a qualidade possuir diferentes significados, de modo geral, ela baseia-se nos aspectos de satisfação, preço justo, funcionalidade do produto e satisfação das expectativas. Nesse sentido, é possível dizer que a qualidade está diretamente ligada com a expectativa que é colocada a partir das necessidades dos usuários finais.

Em relação ao cenário atual de produtividade, Araújo (2012) define a qualidade como uma constante busca pela perfeição que visa agradar aos clientes cada vez mais exigentes e, sobretudo, conscientes da concorrência mercado. A partir dessa necessidade, a Gestão da Qualidade Total é compreendida como uma importante ferramenta de apoio para que as empresas alcancem as vantagens competitivas.

Assim, o ambiente produtivo atual se caracteriza pela importância dos conhecimentos e das tecnologias e como o uso das técnicas modernas é importante para a gestão da qualidade das empresas. De acordo com Dourado e Oliveira (2009), a globalização permitiu que a preocupação com a qualidade se intensificasse assumindo assim a melhoria da eficácia da gestão nas empresas pela busca da competitividade e sobrevivência no mercado.

Conforme aduz Gaither (2006), o alvo dos programas de qualidade total é designar uma organização que produza produtos e serviços que sejam acatados de primeira classe por seus clientes, ou seja, para obter excelência em qualidade, tudo deve ser feito da maneira correta da primeira vez e estar em constante melhoria.

Nesse contexto Favoron (2012), destaca que é essencial que haja uma diferenciação entre a qualidade e a qualidade total.Isso porque, de forma geral, a qualidade se trata de uma avaliação realizada pelo cliente a respeito de determinado produto ou serviço, a fim de verificar se atende ou não as suas expectativas, e a qualidade total, é uma visão mais ampla, voltada para a eficiência de todos os elementos e processos da cadeia produtiva.

Nesse sentido, a Gestão da Qualidade Total é um elemento que aponta a definição da cultura organizacional da empresa voltada para a satisfação do cliente com o uso de ferramentas integradas, com técnicas e treinamentos, envolvendo a melhoria contínua dos processos organizacionais que resultam na qualidade de produtos e serviços.

Sendo assim, Gestão da Qualidade Total se trata de uma filosofia, de um modo de pensar e de agir que se volta essencialmente para a preocupação com o atendimento das necessidades e das expectativas dos clientes.Desse modo, o foco da qualidade sai das especificações do produto e das operações de produção para toda a organização. Para isso, devem-se considerar fatores como: a participação da alta gerência, a criação de equipes multifuncionais, trabalho em equipe, resolução de problemas e aperfeiçoamento dos processos (SASHKIN; KISER, 1994).

A partir disso, é possível dizer que a Qualidade Total decorre da aplicação de melhorias contínuas dos processos das organizações, sendo uma abordagem para a melhoria da competitividade, da eficiência e da flexibilidade através do planejamento organizacional e com o envolvimento de todos da organização (FAVORON, 2012). 
Desse modo, a Qualidade Total leva para as organizações conceitos que se baseiam em mudanças organizacionais, no âmbito dos processos de produção e da forma como as atividades são realizadas. Schmidt (2013) destaca que o que sustenta o foco para a busca das mudanças e melhorias é a ameaça da empresa não sobreviver no mercado sem qualidade e sem a busca contínua pelas melhorias.

Nesse sentido, Campos (2004) destaca que os conceitos de produtividade, de sobrevivência e de competitividade das empresas estão ligados ao lucro, ou seja, quanto mais a empresa produz, mais ela lucra. Isso é o que garante que ela sobreviva e se mantenha competitiva, mas o aumento da produtividade só ocorre quando o produto ou serviço está na preferência dos clientes, pois os clientes esperam qualidade.

A partir do que foi exposto, é possível perceber que, implantar a gestão de qualidade nas empresas tem sucesso à medida que haja comprometimento de todos os envolvidos na organização.

Nesse sentido, existem diversos métodos de gestão para o combate dos desperdícios e dentre esses recursos está o programa 5S, ou Cinco Sensos. Trata-se de um programa que engloba todas as áreas da empresa, pois, vai desde as áreas administrativas à produção. Além disso, abrange os setores dos serviços e também da manutenção, envolvendo todos os colaboradores, ou seja, do mais alto cargo hierárquico aos operadores. Este programa é muito simples, e deve ser liberado pela alta administração, tendo como base a educação, o treinamento e também a prática coletiva, de acordo com Cruz, Borba e Schechtel(2014).

O Programa $5 \mathrm{~S}$ é a base para a qualidade total que foi capaz de transformar, em menos de 20 anos, uma nação que havia sido totalmente destruída por uma guerra em uma potência industrial e econômica. Mas é preciso evidenciar ainda que, não são apenas essas cinco palavras que irão transformar uma nação ou uma empresa. A educação e a coletividade são fundamentais para tal. É preciso ressaltar que complemento ao 5S, nasceu a Teoria dos $8 \mathrm{~S}$.

\subsection{PROGRAMA $8 \mathrm{~S}$}

A qualidade é permeada por conceitos que vão desde o gerenciamento tradicional à Gestão da Qualidade Total. Desse modo, todo esse processo envolve conceitos, filosofias, técnicas e métodos de gestão que foram sendo criados, masque com o tempo passaram por aprimoramento para que assim fosse possível que as organizações passassem a ter os meios adequados para a obtenção de melhores resultados. Dentre as ferramentas usadas nos processos de planejamento de qualidade, destaca-se o Programa 8S.

O Programa 8S, de acordo com Abrantes (2007), trata-se de uma teoria desenvolvida no Brasil como uma continuidade ao programa $5 \mathrm{~S}$. Tem uma filosofia de trabalho que busca a promoção de disciplina nas organizações por meio da conscientização e da responsabilidade de todos os envolvidos nos processos do ambiente organizacional. $\mathrm{O}$ objetivo é tornar o espaço empresarial seguro, produtivo e agradável para o trabalho.

O programa 5S nasceu no Japão logo após a Segunda Guerra Mundial, nos anos 50. Foi desenvolvido por Kaoru Ishikawa, tinhacomo objetivo promover a ordem no caos deixado pela Guerra após a derrota japonesa para as forças aliadas. O programa se mostrou bastante eficaz no que diz respeito a reorganização de empresas e da própria economia do país, que até os dias atuais, é considerado como um dos principais instrumentos para a gestão da qualidade e da produtividade japonesa.

De acordo com Filho (2014), o programa 5S se baseia em cinco sensos e é considerado como a base para a Gestão da Qualidade Total, que consiste em cinco atividades iniciadas com a letra "S" quando pronunciadas em japonês, são elas: Seiri, Seiton, Seiso, Seiketsu e Shitsuke. No Brasil, o programa 5S passou a ser usado entre as décadas de 1980 e 1990 para o aprimoramento dos ambientes de trabalho, com a finalidade da diminuição das perdas e dos desperdícios. Dessa forma, assim como no Japão, tornou-se o ponto de partida para a implementação de outras ferramentas e procedimentos para a execução de sistemas de gestão de qualidade nas empresas.

Desse modo, é possível apontar que, o programa 5S é uma metodologia que é fundamentada a partir da filosofia de maximizar o valor das organizações pela remoção de todos os fatores que não agregam valores para a empresa. Sendo necessário adotar as medidas do programa para obter uma produtividade maior, além de demonstrar para os trabalhadores que, se aprenderem a trabalhar em equipe, além de conseguirem fazer o serviço em menos tempo, vão ter uma maior produtividade com mais excelência para a instituição. Assim, consequentemente conseguirão otimizar o tempo de serviço, que será melhor para ambas as partes.

Com a grande precisão de completar o Programa 5S, foram acrescentados mais três S's (ShikariYaro, Shido e Setsuyaku). Este programa está gerando grandes mudanças no desempenho das pessoas. Além disso, 
colabora para procedimentos de implantação de futuros Programas de Qualidade Total, assim, o 8S pode ser considerado a base para a implantação de outros programas de qualidade (NUNES; FIGUEIRA, 2010).

A empresa necessita de se adequar com as práticas mais sustentáveis, para resultar em colaboradores mais confiantes e motivados a fazer sempre o melhor. Conforme estudos, pode-se perceber que o programa dos $5 \mathrm{~s}$ tem feito com que as empresas consigam se manter organizadas, tendo um ambiente mais agradável, onde os funcionários consigam ser mais ágeis, devido estar tudo em seu devido local.

A criação do programa $8 \mathrm{~S}$ abotoado ao apoio da administração ajuda na organização dos processos, redução de falhas, construção de uma cultura concisa e consciente dentro do estabelecido pela própria organização, e ainda prevenir determinadas doenças decorrentes do trabalho. (SCHNEIDER, 2017).

O $8 \mathrm{~S}$ trouxe inúmeros benefícios para várias empresas, sendo cada vez mais recomendado. Dessa forma, além de proporcionar um ambiente melhor na organização, consegue superar as expectativas dos consumidores. Pois, esse programa traz uma imagem de competência e responsabilidade para com todos e consequentemente uma melhoria na produtividade da organização.Desse modo, os 8S's são:

ShikariYaro - senso de determinação e união: de acordo com Abrantes (2007), este sensoprega a participação, a parceria e a união entre a alta administração da empresa e todos os seus funcionários.Uma vez que, as chaves para este senso são: a liderança, a comunicação e a motivação. Porquanto, quando as organizações buscam a melhoria dos seus processos por meio da mudança de atitudes, o exemplo é essencial. Nesse caso, o exemplo deve vir pela mudança de comportamento da alta administração, pois, somente dessa maneira é possível fazer com que os funcionários se sintam motivados e satisfeitos.

Shido - Senso de educação e treinamento:de acordo com Abrantes (2009), este sensoprega o treinamento profissional e as ações de educação e aprendizagem no ambiente organizacional, uma vez que, tais ações são capazes de qualificar o profissional ao mesmo tempo em que gera crescimento pessoal, por meio do alcance das competências adequadas para a realização de determinado trabalho.

Seiri - Senso de Utilização:este senso prega que, tudo que não for útil para a empresa e para os seus processos, é desnecessário. Desse modo, o que é transmitido por meio do Seiri é quese deve separar tudo o que é útil do que é inútil. Carvalho (2011) completa que,é essencial que seja identificado tudo que possui utilidade certa e separado daquilo que não possui. Assim, tudo que for útil deve estar disponível, isto é, deixar dispostos, no ambiente de trabalho, apenas materiais, equipamentos e ferramentas que realmente sejam necessários.

Seiton - Senso de Organização: este senso refere-se a organizar e identificar os itens e espaços da organização. De acordo com Abrantes (2009), é importante que sejam separados os itens, por meio de uma padronização, para que cada pessoa que chegue àquele ambiente tenha certeza de onde encontrar o que precisa. Sendo assim, esse senso, é necessário para que cada coisa seja deixada em seu devido local, facilitando a organização das atividades da empresa no dia a dia, de modo que seja aumentada a produtividade pessoal e profissional.

Seiso - Senso de Limpeza:É preciso que os ambientes sejam limpos e preservados. Sobre isso, Carvalho (2011) aponta que os colaboradores precisam saber a importância de se trabalhar em um ambiente limpo, pois assim, ele irá buscar meios para evitar que se acumulem sujeiras em seu local de trabalho, deixando o ambiente agradável, limpo, em termos de higiene, saúde pessoal e segurança do trabalho.

Seiketsu - Senso de Higiene, Bem Estar e Segurança: assim como é preciso manter o local de trabalho limpo, deve-se mantê-lo também seguro, cuidando da saúde física, mental e emocional das pessoas. Isso porque, de acordo com Abrantes (2007), ambientes de trabalho limpos, agradáveis e seguros oferecem maior motivação. Carvalho (2011) completa ainda sobre a essencialidade de transmitir para os colaboradores a importância e a necessidade de manter um ambiente de trabalho com higiene, segurança e ordem. Assim, o autor traz como ideia fundamental, "transmitir a importância e necessidade da higiene, pois ela também simula a conservação da limpeza e da ordem". Nesse sentido, é importante que cada pessoa tenha ciência de que o senso de bem estar também é importante e que é necessário zelar pela higiene, deixando o ambiente de trabalho sempre limpo, possibilitando o bem estar dos colaboradores.

Shitsuke - Senso de autodisciplina:este senso é fundamental para manter o Programa. Uma vez que a autodisciplina está voltada para todos os sensos e para a designação de regras claras para que tudo permaneça da forma adequada. De acordo com Abrantes (2009), o Shitsuke é o senso mais difícil na prática, pois se exige uma profunda transformação por parte do indivíduo, é necessário muito respeito e educação com as outras pessoas. Por isso, este senso deve ser praticado todos os dias, para assim virar uma rotina e consequentemente se tornar um hábito, ficando mais fácil a execução do trabalho.

Setsuyaku - Senso de economia e combate ao desperdício: prega sobre a necessidade de conscientizar os indivíduos sobre a importância de economizar e combater o desperdício, pois é necessário que 
todas as pessoas estejam educadas, treinadas e conscientizadas, para assim, ser possível propor o senso de economia. Pois, de acordo com Abrantes (2007), este senso subsidia o estabelecimento de parâmetros e de limites para a aceitação e controle para que o programa como um todo seja acompanhado e medido em seu desempenho.

Com o constante aquecimento do mercado civil, as empresas têm investido em técnicas e novas práticas de gestão com a finalidade de aumentar sua produtividade e reduzir cada vez mais os custos através de novas filosofias de produção. Uma das grandes características da construção civil é o seu elevado percentual de desperdício, acarretado pela falta de planejamento ou gerenciamento, ou até mesmo pela improvisação do planejar e gerir, gerando o desperdício de materiais, mão-de-obra e baixa produtividade.

Mesmo que os instrumentos de gestão da qualidade tenhama possibilidade de serem implantados, em diversos tipos de empresa, bem como o $8 \mathrm{~S}$ seja uma das ferramentas de fácil implementação, as organizações voltadas para a construção civil, possuem pouca intimidade com ferramentas gerenciais, com a qualidade ou mesmo com a integração desses equipamentos para a sua gestão.

Mas é possível destacar que, de nada adiante ter um produto de qualidade se ele não for atrativo para os clientes, contudo para que as empresas sejam competitivas, elas precisam saber gerenciar os seus custos. Dessa forma, podem adotar diversas estratégias possíveis, tais como: a redução de perdas e desperdícios, a redução de paradas e a otimização de processos, eliminando tudo que é desnecessário. Para isso, usa-se a ferramenta 8S.

\section{METODOLOGIA}

\subsection{MÉTODO DE PESQUISA}

O método de pesquisa adotado é o de revisão bibliográfica, que se apoiou em uma abordagem qualiquantitativa para levantamento e análise dos dados. Os autoresMartins e Ramos (2013) conceituam as abordagens da seguinte maneira, quantitativa: tudo que pode ser mensurado em números, classificado e analisado, nela utiliza-se de técnicas estatísticas; já a forma qualitativa: não é traduzida em números, pretendese nela verificar a relação da realidade com o objeto de estudo, obtendo-se várias interpretações de uma análise indutiva por parte do pesquisador.

A pesquisa baseada na metodologia qualitativa tem suas raízes acadêmicas nas ciências sociais, assim, "o que hoje denominamos estudos qualitativos começaram a aparecer no cenário de investigação social a partir da segunda metade do século XIX" (GODOY, 1995).

\subsection{INSTRUMENTOS DE COLETA DE DADOS}

O estudo foi realizado por pesquisa de campo através da aplicação de um questionário que compreende um método abrangente, com o objetivo de realizar a coleta e a análise de dados, assim como abordagens quantitativas e qualitativas de pesquisa.

A coleta de dados foi feita na empresa de construção civil em Palmeiras de Goiás e realizada através da aplicação do questionário do $8 \mathrm{~S}$ com os funcionários da Hozanna Construções.

O presente questionário foi desenvolvido pelosacadêmicospesquisadores deste trabalho e validado de acordo com os colaboradores do canteiro de obras. O convite aos participantes foi realizado pessoalmente.

\subsection{POPULAÇÃO E AMOSTRA}

Para esta pesquisa, desenvolveu-se um estudo de caso para a aplicação do Programa 8S em um canteiro de obras da empresa Hozanna Construções. A Hozanna construções é uma organização familiar que já atua no Município de Palmeiras de Goiás desde o ano de 1989.Atualmente, a empresa possui 27 funcionários, ao todo, e desses, 15 responderam a essa pesquisa. Realizou-se um diagnóstico por meio de observações e entrevistas com os funcionários da empresa quando foram examinados diversos pontos referentes à aplicação do Programa $8 \mathrm{~S}$. 


\section{IVANÁLISE E DISCUSSÃO DOS RESULTADOS}

De acordo com Caperucci et al. (2016), a aplicação de programas como o 5S, ou mesmo o 8S, nas empresas, não se trata da solução de todos os problemas ou dificuldades da instituição. Mas, trata-se de um método simples que tem efeitos que podem ser imediatos e duradouros, tanto para a organização, quanto para os clientes, o meio ambiente e a sociedade. Isso porque, por meio do uso do programa $8 \mathrm{~S}$, as empresas buscam melhorar o seu ambiente e as suas condições de trabalho, tornando-o, de certo modo, um lugar estimulador e que seja capaz de transformar potenciais em realizações.

A apresentação dos resultados da entrevista serão seccionados conforme cada um dos 8 sensos. O primeiro senso a ser verificado, portanto, foi o senso de treinamento, assim, a partir da entrevista, identificou-se que, $80 \%$ dos trabalhadores não conheciam o que era a ferramenta $8 \mathrm{~S}$, como verificado no Gráfico 1 a seguir:

Gráfico 1: Senso de Treinamento (Shido)

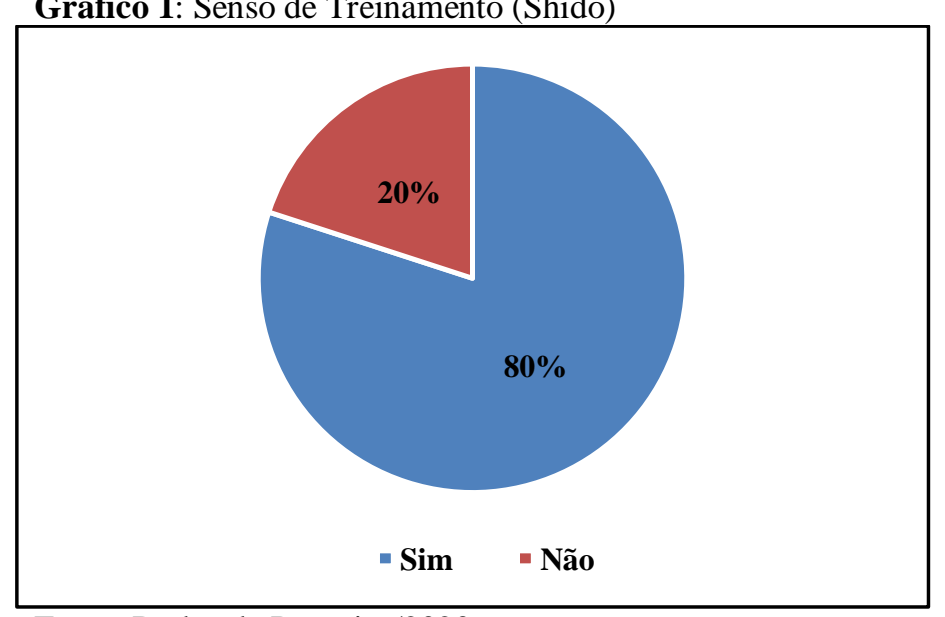

Fonte: Dados da Pesquisa/2020.

Conforme apontado por Abrantes (2007), o senso de treinamento é o que deve envolver todo o programa para a melhoria do ambiente de trabalho pela aplicação do 8S. Visa, principalmente, a orientação para a implantação do programa e, por isso, não se deve levar em conta apenas a reeducação do trabalhador, mas sim a sua qualificação de modo que ele seja motivado para o trabalho.

A partir dos resultados referentes a este senso, reconheceu-se a importância do treinamento para a melhor adequação dos trabalhadores para o uso e aplicação dos sensos no local de trabalho. o senso de treinamento foi aplicado junto aos colaboradores após o diagnóstico e a sensibilização deles sobre a aplicação do $8 \mathrm{~S}$, ou seja, este sensodeve envolver todo o planejamento para a aplicação e uso da ferramenta na empresa.

Como verificado, a grande maioria dos funcionários entrevistados não conheciam a ferramenta $8 \mathrm{~S}$, e por isso, foi indispensável a realização do treinamento dos colaboradores sobre esse instrumento. A partir desse treinamento de sensibilização, os trabalhadores puderam identificar diversos problemas existentes no canteiro que poderiam ser resolvidos com a aplicação do $8 \mathrm{~S}$. Um exemplo pontual, são os entulhos espalhados pelo canteiro, falta de organização, identificação e limpeza dos materiais, ferramentas de trabalho e precariedade no aspecto visual da obra. Após a capacitação para a sensibilização dos funcionários sobre o dispositivo, foi iniciado o trabalho com os sensos.

Em relação ao senso de utilização, ou seja, o segundo senso,foram apresentados os seguintes resultados: o gráfico 2 e 3 apresentam os dados quanto ao excesso de materiais no local de trabalho e o funcionamento dos equipamentos: 
Gráfico 2: Senso de Utilização (Seiri)Materiaisem excesso ou desnecessários

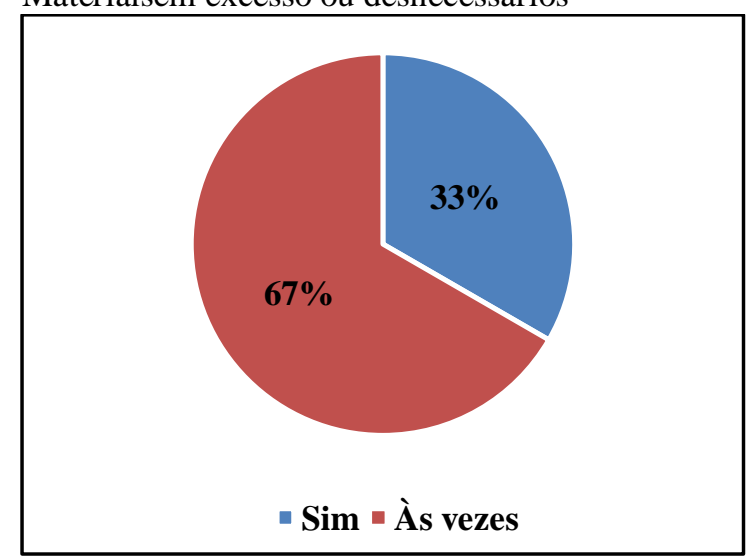

Fonte: Dados da Pesquisa/2020.
Gráfico 3: Senso de Utilização (Seiri) funcionamento dos equipamentos

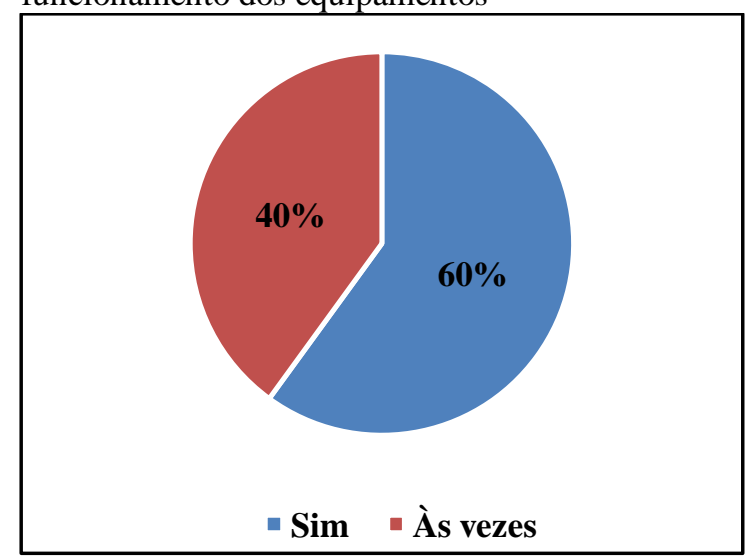

Fonte: Dados da Pesquisa/2020.

A partir dos resultados acima, é possível verificar que, 67\% (10) e 33\% (5) dos funcionários consideram respectivamente que, às vezes, e sim, existe excesso de materiais ou materiais desnecessários no canteiro de obras. Também, como verificado no Gráfico 3, acima, 60\% (9) apontam que a empresa possui todos os seus equipamentos funcionando perfeitamente, e $40 \%$ (6) dos funcionários, apontam que, todos os equipamentos de trabalho funcionam às vezes.

Desse modo, vê-se a necessidade de otimizar o espaço no canteiro de obras em detrimento de equipamentos e materiais que não são essencialmente úteis para o processo de produção do canteiro de obras. Quanto à identificação dos equipamentos que são usados pelos trabalhadores:

Gráfico 4: Senso de Utilização (Seiri) - Identificação dos equipamentos

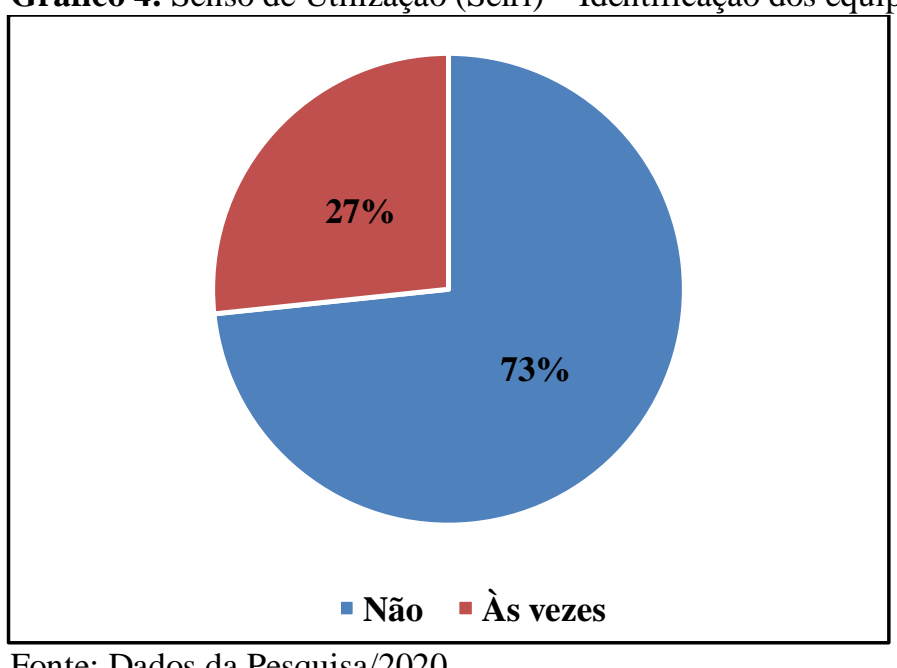

A partir dos resultados apresentados no Gráfico 4 acima, verifica-se que, $73 \%$ apontam que os materiais e ferramentas de trabalho não são identificados, enquanto que, na opinião de $27 \%$ dos funcionários, os equipamentos são identificados, às vezes. A partir desses resultados, é possível apontar que, esse senso consiste na atividade de separação de objetos e/ou documentos, informações e serviços que devem ser categorizados em úteis e inúteis. Dessa forma, os que forem categorizados como inúteis, devem ser descartados de maneira responsável.

Corroborando assim com Carvalho (2011) que aponta a importância da identificação e da distinção de tudo que tem utilidade para os processos da empresa, uma vez que é fundamental que seja deixado no ambiente de trabalho apenas o que é necessário, descartando o que não é usado e armazenando o material que possa estar em excesso. 
Durante o processo de aplicação desse primeiro senso, foi realidade a identificação dos materiais e ferramentas que fossem úteis para o trabalho no canteiro de obras, separando e deixando o fácil acesso apenas ao que fosse indispensável para o trabalho. Essa etapa foi realizada com a ajuda dos trabalhadores do canteiro, uma vez que eles são os responsáveis pelo uso diário desses equipamentos.

O terceiro senso a ser tratado, foi o senso de organização (Seiton), os aspectos que foram considerados, levaram em conta, a organização do local de trabalho, o empenho dos colaboradores em manter o local organizado, a organização dos equipamentos e materiais e a identificação dos locais adequados para a disposição de materiais e equipamentos:

Gráfico 5: Senso de organização (Seiton) Organização do local de trabalho

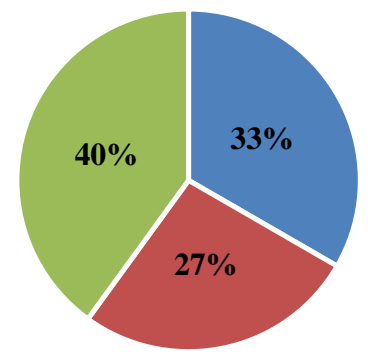

- Sim $=$ Não $=$ Às vezes

Fonte: Dados da Pesquisa/2020.
Gráfico 6: Senso de organização (Seiton) identificação dos locais

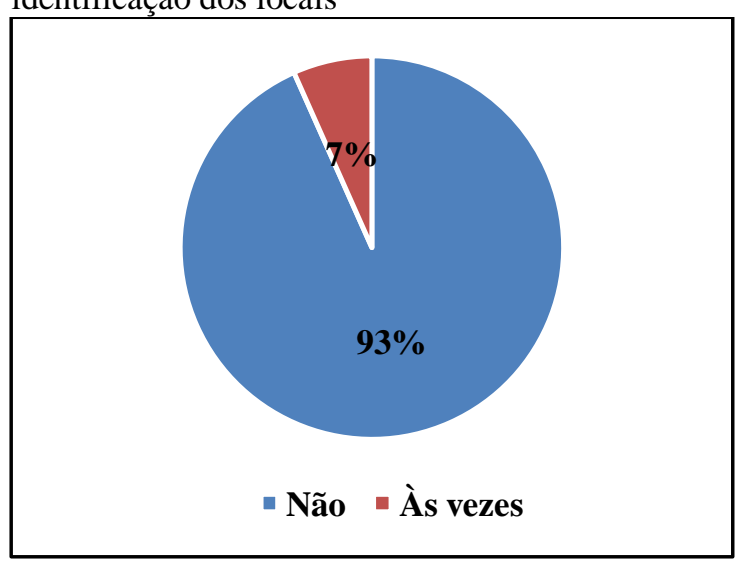

Fonte: Dados da Pesquisa/2020.

Conforme verificado, no Gráfico 5, 40\% (6) dos funcionários consideram que o ambiente de trabalho é organizado às vezes, $33 \%$ (5) apontam que o ambiente de trabalho é organizado, e 27\%(4) apontam que o ambiente de trabalho não é organizado. O Gráfico 6, mostra ainda que, 93\% (14) dos funcionários apontam que o canteiro de obras não possui identificação nos locais para armazenamento de equipamentos e materiais.

Desse modo, considerando o que foi levantado por Abrantes (2009), esse senso é que identifica e organiza os espaços de uma empresa, ou seja, corresponde em manter o que é necessário sempre organizado em local acessível de identificação e fácil acesso, com segurança quanto à identificação dos espaços. Desse modo, conforme apresentado no gráfico 7 abaixo, 73\%(11) apontam que há local apropriado para o armazenamento dos equipamentos e apenas $27 \%$ (4) apontam que, às vezes.

Verifica-se comparando os Gráficos 5, 6 e 7 certa incongruência nas respostas, uma vez que,a maioria dos funcionários considera que não há organização no ambiente de trabalho e que os locais não são identificados. Mas, $73 \%$ deles reconhecem que na empresa existe um local apropriado para o armazenamento de materiais e equipamento. Os resultados permitiram concluir que este senso precisa ser implementado na empresa.

Conforme verificado, o senso de organização é um dos principais a serem implementados na empresa, e espera-se que com a implementação deles, sejam gerados resultados positivos.Uma vez que, conforme o gráfico 8 abaixo, 47\% (7) dos funcionários se empenham em manter o local de trabalho organizado, 33\%(5) às vezes demonstram esse empenho e somente 20\%(3) não se esforçam em manter o local de trabalho organizado. 
Gráfico 7: Senso de organização (Seiton) - Local apropriado para ferramentas

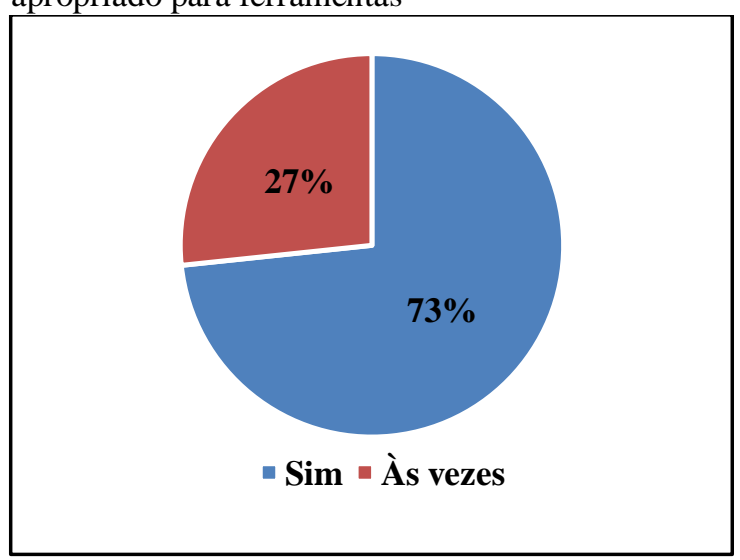

Fonte: Dados da Pesquisa/2020.
Gráfico 8: Senso de organização (Seiton) Empenho dos funcionários em organizar

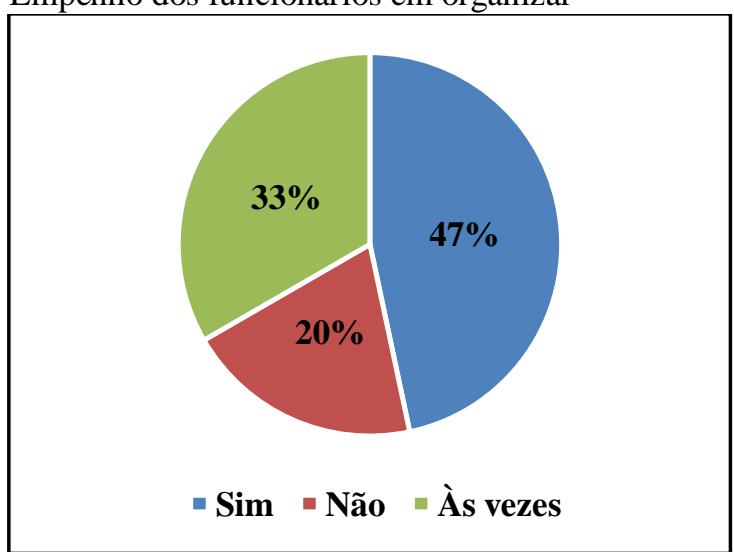

Fonte: Dados da Pesquisa/2020.

De um modo geral, para a aplicação desse senso é fundamental que os itens, tais como: ferramentas, equipamentos e materiais necessários para serem usados, de maneira rápida e segura, sejam identificados e organizados de forma fácil para que após o seu uso, sejam recolocados no local adequado e em boas condições de uso. Pois, conforme apontado por Abrantes (2009), o ambiente de trabalho deve ser padronizado de modo que as pessoas tenham certeza de que em determinado local irão encontrar o que precisam.

Por isso, o processo de organização foi realizado junto ao senso de utilização, uma vez que os equipamentos e materiais de maior frequência de uso foram colocados mais acessíveis que os materiais de uso esporádicos ou de uso pouco frequentes. Foram colocadas etiquetas e placas para identificar os espaços para o armazenamento dos materiais, bem como os locais de descarte.

Evidencia-se assim, o senso de limpeza (Seiso), que consiste em manter o ambiente de trabalho agradável e seguro, bem como detectar problemas potenciais de desperdícios ou mesmo que possam gerar riscos para a segurança dos colaboradores.

A respeitodo senso de limpeza, foi possível identificar, que de certo modo, esse senso já existe entre os funcionários, já que, como destacado no gráfico 9, abaixo, os colaboradores possuem o hábito de fazer a limpeza das suas ferramentas, pois, como destacado por $73 \%$ (11) deles, as ferramentas são sempre limpas e apenas 27\%(4) afirmam que realizam a limpeza às vezes.

Já em relação à limpeza geral, no posto ou local de trabalho, 60\%(9) dos funcionáriosdeclararam que realizam a limpeza todos os dias ao final do expediente, enquanto que, 40\%(6) afirmam que essa limpeza ocorre às vezes.

Gráfico 9: senso de limpeza (Seiso) - As ferramentas são limpas

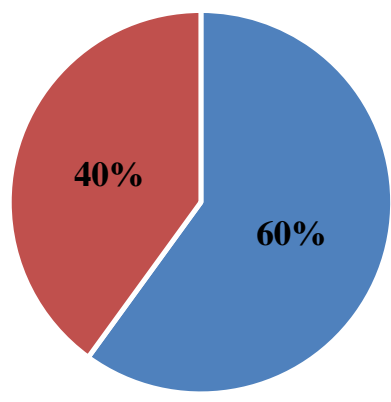

- Sim - Às vezes
Gráfico 10: senso de limpeza (Seiso) - Limpeza Geral

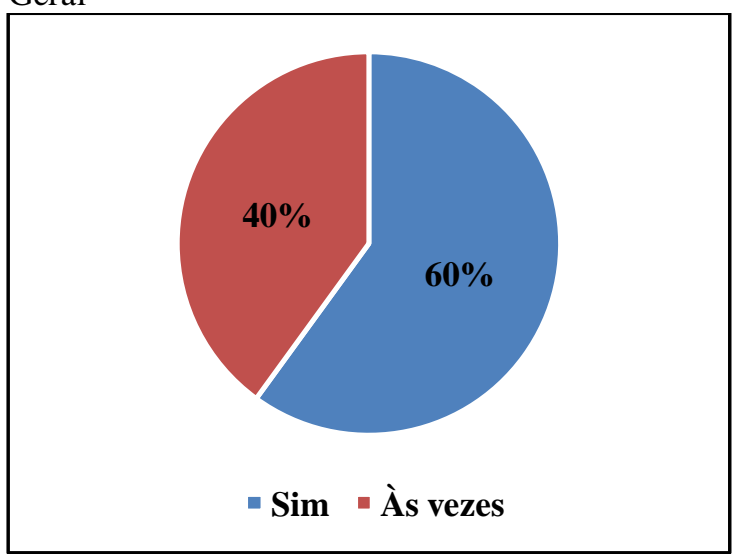

Fonte: Dados da Pesquisa/2020. 
Desse modo, é possível apontar que, o senso de limpeza está diretamente ligado com os sensos de utilização e organização, uma vez que, à medida que ocorria a separação dos materiais e ferramentas para a sua organização, ocorria a limpeza do canteiro, e no processo, um local adequado para a disposição dos resíduos e entulhos da obra foi estabelecido.

A limpeza do canteiro passou a ser realizada, de forma frequente, uma vez que os funcionários passaram a compreender a importância desse senso para o bem estar no trabalho. Os equipamentos e ferramentas também começaram a ser limpos todos os dias, no final do expediente, visto que ficou determinado que, cada trabalhador seria o responsável pela limpeza do seu posto de trabalho e das suas ferramentas de uso diário, bem como a organização do seu material de uso.

O próximo senso a ser tratado é o senso de bem estar e segurança (Seiketsu):

Gráfico 11: senso de Bem Estar e Segurança (Seiketsu): local de trabalho ideal

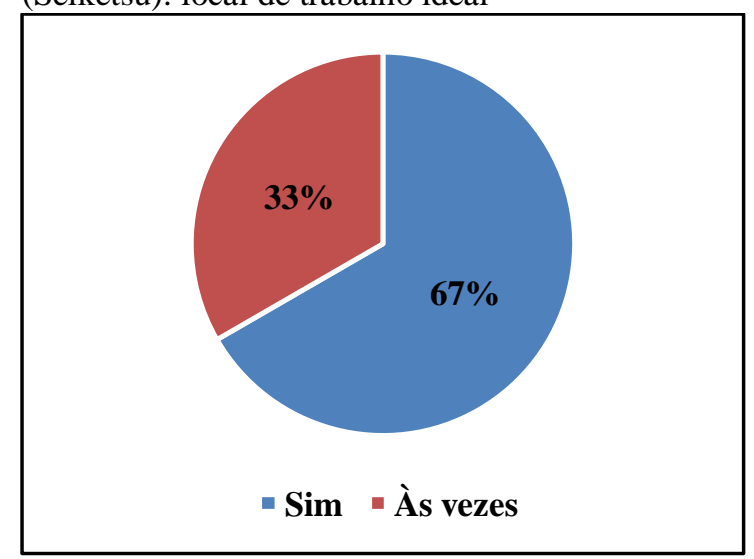

Fonte: Dados da Pesquisa/2020.
Gráfico 12: senso de Bem Estar e Segurança (Seiketsu): trabalhador motivado

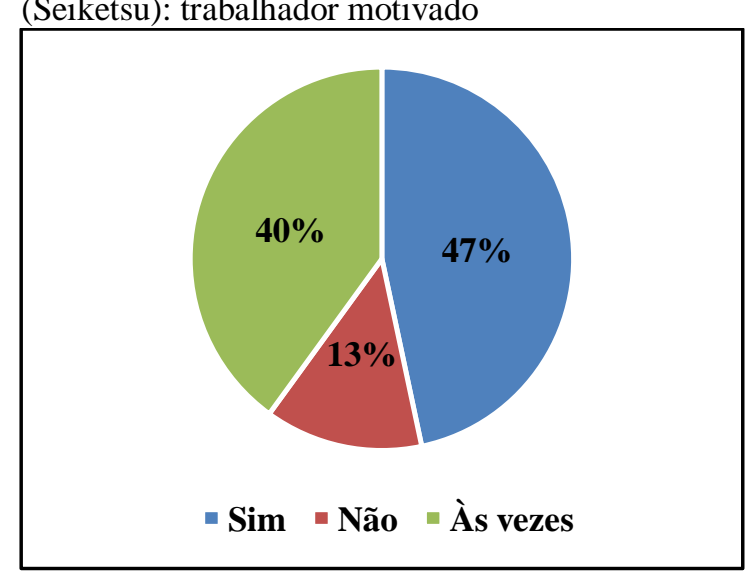

Fonte: Dados da Pesquisa/2020.

Esse senso está relacionado com a normatização para o bem-estar e para a segurança em que suas principais ações estão baseadas na limpeza, higiene e boas condições de trabalho, que devem envolver os bons estímulos para os colaboradores. Como pode ser verificado no gráfico, 11, 33\% dos trabalhadores consideram que o local de trabalho seja ideal somente às vezes, indicando que há possibilidades para melhorias, e junto a isso, buscou-se saber se os funcionários se sentem motivados:

A partir do gráfico 12 , foi possível perceber que, embora $47 \%$ dos trabalhadores se sintam motivados na empresa, uma parcela grande de $40 \%$ (6), sentem essa motivação somente às vezes e $13 \%$ (2) não se sentem motivados em trabalhar na organização. Sobre o uso de EPI, verificou-se que, a grande maioria considera o uso de EPI importante, visto que, apenas $13 \%$ acham que o uso seja fundamental somente às vezes. E ainda sobre o cumprimento de normas e horários 60\%(9) dos funcionários pontuam que são cumpridos, e 40\% (6) apontam que isso ocorre às vezes. 
Gráfico 13:Senso de Higiene, Bem Estar e Segurança (Seiketsu): uso de EPI

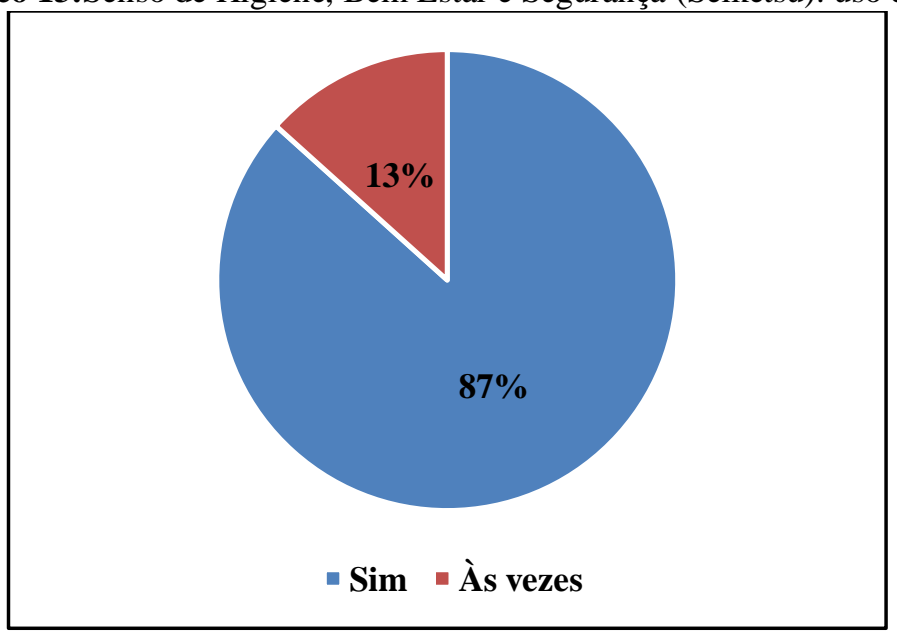

Fonte: Dados da Pesquisa/2020.

Na Hozanna Construções, a aplicação desse senso teve como foco os problemas apontados em relação à proteção dos trabalhadores. Mas apesar dos colaboradores reconhecerem a importância do uso de EPIs, foi observado que não eram fornecidos todos os materiais necessários para a execução dos serviços. Por isso, a empresa se prontificou em fornecer os EPIs restantes, bem como implantar alguns EPCs depois de identificada a inexistência no canteiro. As aplicações dos sensos anteriores também foram cruciais para este resultado, pois a organização e limpeza no canteiro contribuíram de forma significativa para manter a segurança e a saúde dos trabalhadores.

Desse modo, o próximo senso a ser tratado é o senso de autodisciplina (Shitsuke): ele envolve o respeito a tudo que foi estabelecido com o planejamento e a aplicação da ferramenta, ou seja, é quando todos passam a respeitar e a adotar o que foi estabelecido, e para isso, deve-se ainda dar espaço para novas sugestões e melhorias constantes.

Gráfico 14: senso de autodisciplina (Shitsuke): responsabilidades individuais

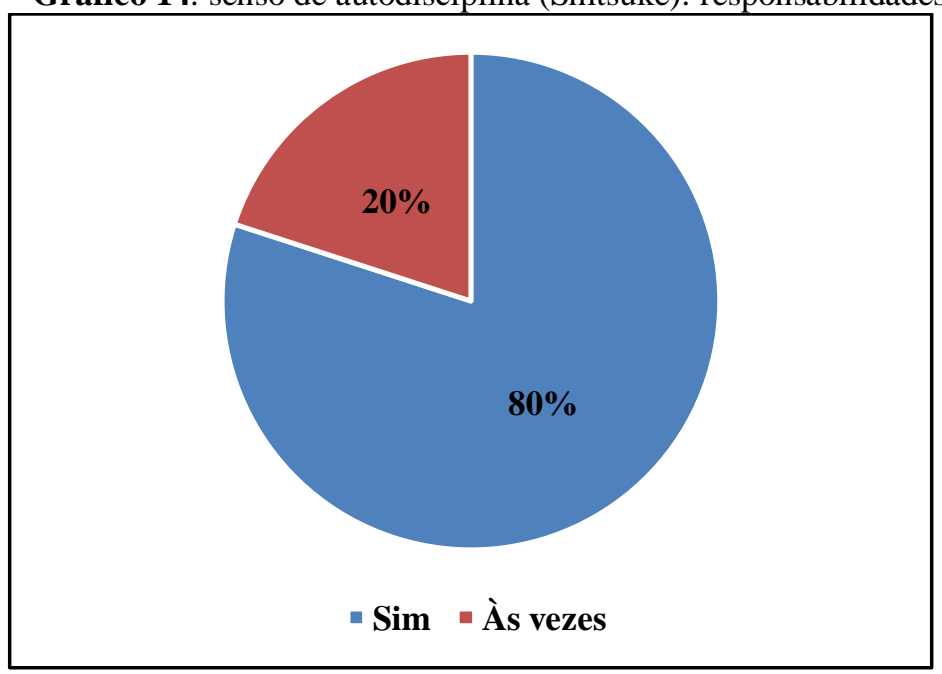

Fonte: Dados da Pesquisa/2020.

Quando indagados sobre as suas responsabilidades individuais para a melhoria do local de trabalho, $80 \%$ (12) dos funcionários disseram que estão sim, cientes, e 20\%(3) apontam que se sentem cientes das suas responsabilidades somente, às vezes. De acordo com Abrantes (2009), o senso de autodisciplina é essencial para manter o programa $8 \mathrm{~S}$ na empresa, pois, determina que as regras estabelecidas sejam mantidas e permaneçam claras. 
Por isso, é difícil mensurar esse senso, já que somente com observações constantes do ambiente e do comportamento dos trabalhadores é possível perceber se esse dispositivo está sendo efetivado. Mas, buscou-se a adoção da autodisciplina no canteiro com algumas medidas para que este senso fosse consolidado. Assim, a empresa passou a adotar o Diálogo Diário de Segurança, para repassar os passos referentes ao 8S diariamente para os trabalhadores, bem como as estratégias que deveriam ser adotadas, no decorrer do trabalho para a proteção adequada e para as tarefas que devem ser executadas no dia-a-dia no canteiro. Além disso, passou a dar espaço para os colaboradores expressarem suas sugestões e opiniões de melhorias.

Tem-se também o senso de determinação e união (ShikariYaro), ele diz respeito à integração de toda a empresa nessa nova filosofia, ou seja, diz respeito à motivação, liderança e comunicação.

A respeitoda participação de todos para a melhoria do programa continuamente, conforme o gráfico 15 , $60 \%$ (9) dos funcionários afirmam que sim, e 40\% (6) afirmam que às vezes. Também, quando perguntado aos trabalhadores sobre a participação dos superiores no empenho às melhorias do programa, como mostrado no gráfico 16, 80\% (12) dizem que eles estão empenhados e 20\% (3) afirmam que percebe esse empenho, às vezes:

Gráfico 15: Senso de Determinação e União (ShikariYaro): união da equipe para a melhoria do programa

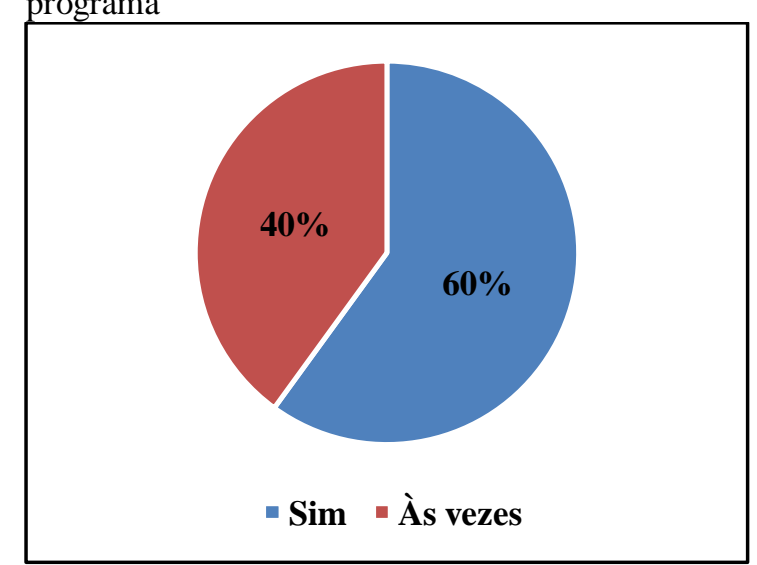

Fonte: Dados da Pesquisa/2020.
Gráfico 16: senso de determinação e união (ShikariYaro)

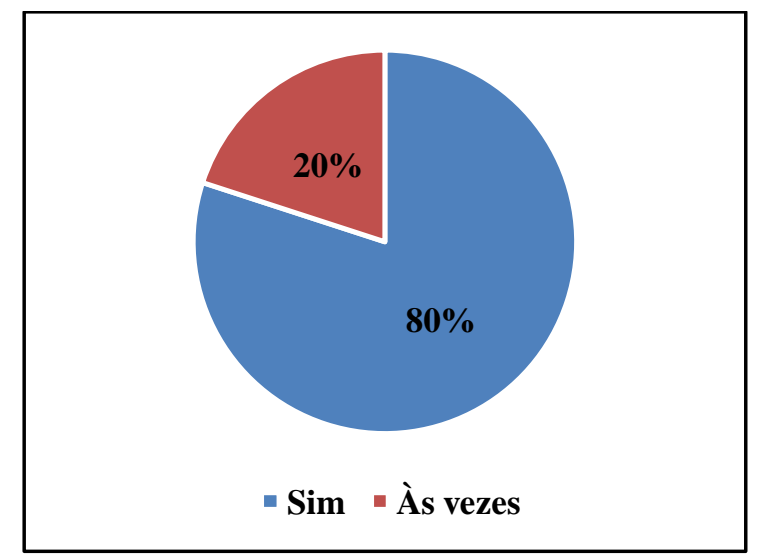

Fonte: Dados da Pesquisa/2020.

Desse modo, a partir da aplicação dos sensos anteriores, fortalece-se o senso de determinação e união de modo que os funcionários passam a ver o seu local de trabalho como ideal e começam a ter motivação para a realização do seu trabalho. Isto é, os trabalhadores passam a sentir que estão sendo tratados com respeito, igualdade e recebendo boas condições de trabalho. Sabe-se que para isso, é essencial a participação da liderança.

Quanto ao senso de economia e combate aos desperdícios (Setsuyaku), no que diz respeito à concepção dos trabalhadores entrevistados sobre evitar desperdícios no local de trabalho, todos reconhecem a importância disso. Ao serem perguntados sobre o que acham da economia no local de trabalho 80\%(12) dos funcionários acreditam que essa economia é possível, enquanto que $20 \%$ (3) acreditam que é possível somente, às vezes.Ou seja, em determinadas situações, de acordo com os funcionários não é possível a realização de economia.

Desse modo, a implementação do programa 8S na Hozanna Construções, foi vista como um processo de educação e trouxe uma série de melhorias para a empresa, principalmente no que diz respeito ao bem-estar, motivação e segurança de todos os colaboradores.

\section{VCONSIDERAÇÕES FINAIS}

O objetivo deste trabalho consistiu em verificar como a implantação do programa $8 \mathrm{~S}$ pode trazer inúmeros benefícios para a organização e para os colaboradores da construção civil, e para isso, foi realizado um diagnóstico e implantação da ferramenta no canteiro de obras da HozannaConstruções, uma pequena empresa de construção civil localizada na cidade de Palmeiras de Goiás. 
Percebeu-se que, havia alguns problemas que precisavam ser solucionados na empresa, mas que o uso das ferramentas associadas ao $8 \mathrm{~S}$ traria melhorias para esses impasses. Para isso, os colaboradores participantes da pesquisa receberam um pequeno treinamento para a sensibilização sobre o $8 \mathrm{~S}$, e logo em seguida, foram implantadas as ações referentes ao dispositivo.

Com a implantação do programa, puderam ser observadas diversas mudanças no canteiro de obras, como por exemplo, a organização e limpeza de materiais, ferramentas e equipamentos usados no canteiro de forma adequada. Além disso, a limpeza do canteiro, diminuição de materiais desperdiçados no espaço, equipamentos e ferramentas separados por não agregarem valor à obra.

Mas, apesar de todos esses benefícios que foram gerados de imediato com a implantação do programa $8 \mathrm{~S}$, não é possível afirmar ainda que tais ações se tornarão parte do dia a dia da empresa e do senso de autodisciplina dos funcionários.Mas, no decorrer da realização deste trabalho, e a partir das observações realizadas no pós-implantação do programa, foi possível verificar que, o dispositivo já causou impactos na empresa, de tal modo que, inclusive os proprietários passaram a tomar ações para a continuidade do programa, com pequenos atos para motivar os funcionários a manterem resultados positivos.

A empresa se comprometeu, sobretudo em treinar todos os funcionários e inclusive os novos colaboradores para a aplicação das ferramentas do $8 \mathrm{~S}$ para que o programa possa ser efetivamente incorporado nainstituição em seus futuros canteiros de obra. Pelo fato de ser um programa simples, de fácil implantação e sem custos, os trabalhadores mesmo aqueles que não conheciam efetivamente o 8S, conseguiram implantá-lo. Mas, por necessitar de melhorias constantes, foi criada na empresa uma equipe voluntária de colaboradores que passaram a ser responsáveis pelo acompanhamento e medição das tarefas relacionadas com cada um dos sensos, uma vez que este é um processo que exige persistência e paciência.

Após a elaboração do presente trabalho, foi possível concluir que, é de suma relevância aplicar os $8 \mathrm{~S}$, para que além da empresa, os colaboradores possam contribuir com a sua parte, tanto em organização, quanto em limpeza e trabalho em equipe, com o objetivo de trazer um melhor resultado para a instituição, bem como para si próprio. Ou seja, trabalhar com mais dedicação e a empresa trazer inovações para que os trabalhadores tenham motivação e conhecimento para contribuir uns com os outros.

\section{REFERÊNCIAS}

[1] ABRANTES, J. Programa 8S: Da Alta Administração à Linha de Produção. 2 ed. Rio de Janeiro: Interciência, 2007.

[2] ABRANTES, J.Gestão da Qualidade. Rio de Janeiro: EditoraInterciência, 2009

[3] AMBROZEWICZ, Paulo Henrique Laporte. Gestão da qualidade na administração pública: histórico, PBQP, conceitos, indicadores, estratégia, implantação e auditoria. São Paulo: Atlas, 2015.

[4] ARAÚJO, Luís César G. Organização, sistemas e métodos e as tecnologias de gestão organizacional: arquitetura organizacional, benchmarketing, empowerment, gestão da qualidade total, reengenharia. 4. ed. São Paulo: Atlas, 2012.

[5] CAMPOS, Vicente Falconi. TQC: Controle da Qualidade Total (no estilo japonês). $8^{\text {a }}$ Ed. Nova Lima: INDG Tecnologia e ServiçosLtda, 2004.

[6] CAPERUCCI, Julia Nayara et al. A aplicação do programa 5s em uma indústria metalúrgica Indústria de Embalagens Metálicas de Lins - SP. Trabalho de Conclusão de Curso (Monografia). Curso de Administração, Centro Universitário CatólicoSalesiano, 2016, 60p.

[7] CARVALHO, Pedro Carlos de. O programa 5S e a qualidade total. 5. ed. São Paulo: Alínea, 2011.

[8] COSTA NETO, Pedro L. de O.; CANUTO, Simone A. Administração com qualidade: conhecimentos necessários para a gestão moderna. São Paulo: Blucher, 2010.

[9] CRUZ, Cristiana M. et al. Benefícios e dificuldadesna implantação e manutenção do Programa 5S em um hospital da região dos Campos Gerais. In: Congresso Internacional de administração. Ponta Grossa, PR. Brasil. 2014. 
[10] DOURADO, Luiz Fernandes (Coord.); OLIVEIRA, João Ferreira de; SANTOS, Catarina de Almeida. A qualidade da educação: conceitos e definições. Brasília: INEP, 2007.

[11] FAVARON, Fabio Luiz Lourenco; SANTOS, Neusa Maria Bastos F.; DOS SANTOS, Roberto Fernandes. Desempenhofinanceiro das empresas do setor de energia elétrica: um estudo com as empresas participantes do Prêmio Nacional da Qualidade. In: Anais do Congresso Brasileiro de Custos-ABC. 2013.

[12] VIEIRA FILHO, Geraldo. Gestão da qualidade total: uma abordagem prática. 5. ed. Campinas: Alínea, 2014.

[13] GAITHER, Norman; FRAZIEN, Greg. Administração da produção e operações. 8. ed. São Paulo: Thomsom Learning, 2006.

[14] GARVIN, David A. Gerenciando a qualidade: a visão estratégica e competitiva, Rio de Janeiro: Qualitymark, 2002.

[15] GODOY, Arilda S. Introdução à pesquisa qualitativa e suas possibilidades. Revista de administração de empresas. São Paulo, v.35, n.2, p.57-63.Mar/Abr 1995.

[16] LUCINDA, Marco Antônio. Qualidade: Fundamentos e práticas para cursos de graduação. Rio de Janeiro: Bradsport, 2010.

[17] MARTINS, Ronei Ximenes; RAMOS, Rosana.Metodologia de pesquisa: guia de estudos. Lavras: UFLA, 2013.

[18] OLIVEIRA, José Augusto de et al. Um estudosobre a utilização de sistemas, programas e ferramentas da qualidade em empresas do interior de São Paulo. Production, v. 21, n. 4, p. 708-723, 2011.

[19] NUNES, CECB; FIGUEIRA, ASM. Implantação do Programa 5S e Ferramentas de Melhoria de Qualidade em Uma Micro-Empresa de Design. XXX Encontro Nacional de Engenharia de Produção. São Carlos, SP, Brasil, 2010.

[20] SASHKIN, Marshall; KISER, Kenneth J. Gestão da Qualidade Total Na Prática: O que é TQM, como usá-la e como sustentá-la a longo prazo. Campus, 1994.

[21] SCHMIDT, Maria LuizaGava. Qualidade total e certificação ISO 9000: história, imagem e poder. Scielo. Disponível em:< http://www.scielo.br/>. Acesso em: 01 set. 2020.

[22] SCHNEIDER, Vívian; MALLMAN, F. M. Implantação da ferramenta de Qualidade " 5 S" em empresa de embalagens de papelão. Acessoem: 01 set. 2020, v. 2, 2017.

Questionário de pesquisa:

\section{APÊNDICE}

1: Você acredita que seu local de trabalho seja ideal?

Sim ( ) Não ( ) Ás vezes ( )

2: Você acredita que seu local de trabalho é organizado?

Sim ( ) Não ( ) Ás vezes ( )

3: Você se empenha para manter o seu local de trabalho organizado?

Sim ( ) Não ( ) Ás vezes ( )

4: Os materiais de trabalho que se utiliza estão identificados?

Sim ( ) Não ( ) Ás vezes ( )

5: Você acredita que seja importante a identificação dos materiais de trabalho?

Sim ( ) Não ( ) Ás vezes ( )

6: Você se sente motivado a trabalhar nesta empresa?

Sim ( ) Não ( ) Ás vezes ( )

7: Você acha importante o uso de EPI's no seu local de trabalho?

Sim ( ) Não ( ) Ás vezes ( )

8: Você sabe o que significa o Programa 8 Sensos (8S)?

Sim ( ) Não ( ) Ás vezes ( ) 
9: Você acredita com a implementação do 8s na empresa, vai melhorar sua produtividade?

Sim ( ) Não ( ) Ás vezes ( )

10: Todos conhecem as suas responsabilidades para manter o local organizado?

Sim ( ) Não ( ) Ás vezes ( )

11: O seu superior está preocupado em melhorar continuamente a prática do $8 \mathrm{~S}$ ?

Sim ( ) Não ( ) Ás vezes ( )

12: Todos estão preocupados em melhorar continuamente a prática do $8 \mathrm{~S}$ ?

Sim ( ) Não ( ) Ás vezes ( )

13: Todos os colaboradores participaram da explicação do 8S?

Sim ( ) Não ( ) Ás vezes ( )

14: Todos os equipamentos de trabalho estão funcionando corretamente?

Sim ( ) Não ( ) Ás vezes ( )

15: Existem materiais em excesso ou desnecessário no local de trabalho?

Sim ( ) Não ( ) Ás vezes ( )

16: As ferramentas de trabalho estão em seu local apropriado?

Sim ( ) Não ( ) Ás vezes ( )

17: Os locais estão identificados com etiquetas?

Sim ( ) Não ( ) Ás vezes ( )

18: As ferramentas de trabalho estão sempre limpas?

Sim ( ) Não ( ) Ás vezes ( )

19: No final do expediente, é realizado uma limpeza geral no local?

Sim ( ) Não ( ) Ás vezes ( )

20: Você acha importante o uso de EPI's no seu local de trabalho?

Sim ( ) Não ( ) Ás vezes ( )

21: Os EPI's estão sendo utilizados?

Sim ( ) Não ( ) Ás vezes ( )

22: Horários e normas são cumpridos?

Sim ( ) Não ( ) Ás vezes ( )

23: Você está ciente das suas responsabilidades individuais?

Sim ( ) Não ( ) Ás vezes ( ) 